Article

\title{
Summer Thermal Comfort and Self-Shading Geometries in Passivhaus Dwellings: A Pilot Study Using Future UK Climates
}

\section{Yahya Lavafpour * and Steve Sharples}

School of Architecture, University of Liverpool, Abercromby Square, Liverpool L69-7ZN, UK; E-Mail: steve.sharples@liverpool.ac.uk

* Author to whom correspondence should be addressed; E-Mail: y.lavaf-pour@liverpool.ac.uk; Tel.: +44-7572-495581.

Academic Editor: Adrian Pitts

Received: 16 July 2015 / Accepted: 26 August 2015 / Published: 27 August 2015

\begin{abstract}
This study uses numerical thermal simulation to investigate the potential use of building geometry to eliminate or reduce current and future thermal discomfort overheating risk in UK Passivhaus dwellings. The study focused on the optimum inclination of a south façade to make use of the building shape to self-protect itself. Dynamic simulation modelling software was used to test a range of different inclined façades with regards to their effectiveness in reducing overheating risk. The research found that implementing a tilted façade could completely eliminate the risk of overheating for current UK climates, but with some consequences for natural ventilation and daylighting. Future overheating was significantly reduced by the tilted façade. However, geometric considerations could not eradicate completely the risk of thermal discomfort overheating, particularly by the 2080 s.
\end{abstract}

Keywords: geometry; passivhaus; overheating; climate change

\section{Introduction}

It has become increasingly evident that buildings contribute significantly to the serious environmental problems of the planet, especially in terms of the fossil fuel energy used to service the built environment. Consequently, in recent decades greater attention has been paid to reducing energy consumption in buildings. EU countries have adapted their building regulations to produce new buildings with nearly-zero energy consumption by 2020 . One example of the low energy standards was 
introduced in Germany by Passivhaus Institute. In the UK a zero carbon new buildings target was announced by the UK government in December 2006 and a national target was set to reduce $80 \%$ of $\mathrm{CO}_{2}$ emission below 1990 level by 2050 [1]. A number of energy efficient strategies have been employed in the UK housing sector to reduce energy consumption for heating demand, including the growing implementation of the Passivhaus standard. For the last few decades thermal insulation has been the most dominant and frequently used intervention for a range of building types in the UK. Much of the focus on the new build and refurbishment in the UK has concentrated on thermal comfort during the winter and on the reduction of space heating demand. However, as suggested by UK Climate Projections from the Meteorological Office [2] the increase in extreme weather events, such as heat waves, calls for the study of overheating risks in the summer period as well.

Although the majority of energy efficient standards have been successful in terms of reducing heating demand, several low-energy buildings have experienced problems with overheating, especially in summer time. Most of the interventions on reducing overheating have focused on users living in these buildings adapting to a specific behaviour to obtain thermal comfort, such as efficient operation of shading blinds or the use of a mechanical ventilation with heat recovery (MVHR) system to enhance ventilation. However, some other interventions have focused on the design of the building envelope to obtain thermal comfort in warm spells of a year. One of the stimuli for the current research was the possibility of using the building's geometry to be able to passively and consistently obtain thermal comfort via robustness of the building design. The research argues that self-shading geometric design of the building envelope can possibly recover some of the gap in the overall building performance that is created by occupants using overheating controls either incorrectly or not at all.

\subsection{The Passivhaus Standard and Literature Review}

The main concern of the Passivhaus Standard is to substantially reduce the requirements for space heating by introducing a "fabric first" approach to the design criteria, i.e., applying high levels of insulation and airtightness to the thermal envelope. To obtain Passivhaus certification a building needs to meet a few main criteria [3]:

- Maximum specific space heat demand no more than $15 \mathrm{kWh} / \mathrm{m}^{2}$ of floor area;

- Overall energy demand (including space heating and cooling) no more than $120 \mathrm{kWh} / \mathrm{m}^{2}$;

- Airtightness no more than $0.6 \mathrm{~h}^{-1}$ at $50 \mathrm{~Pa}$;

- For thermal comfort air temperatures in the living areas must not exceed $25{ }^{\circ} \mathrm{C}$ for more than $10 \%$ of the hours in a given year.

There is also a maximum cooling demand for climates where active cooling is needed. However, this is for climates where the external air temperature does not drop low enough to create a benefit from night time purge ventilation cooling. Therefore, for residual buildings the Passivhaus standard allows an annual cooling energy of $15 \mathrm{kWh} / \mathrm{m}^{2}$ to be used [4].

For Passivhaus, the $U$-values of the building's solid envelope and glazing should be no more than 0.15 and $0.80 \mathrm{~W} / \mathrm{m}^{2} \mathrm{~K}$, respectively. Passivhaus dwellings benefits from large areas of south-facing glazing to capture passive solar gain. The Passivhaus Primer [5] states "In order to benefit from the useful solar gains a Passivhaus requires the glazing to be optimised on the south façade with reduced 
glazing on the (other) façade(s)". Solar gains make up a significant component of the free heat gains available to a Passivhaus during the heating season and large windows themselves become radiators for the room to offset some of the energy required for heating [6]. In addition, large windows provide good daylight levels and pleasant views for occupants. However, large areas of south-facing glazing, coupled with very high levels of thermal insulation and air tightness and the potentially elevated summer temperatures of future UK climates, means that the risk of summer overheating needs to be taken into consideration for future developments of Passivhaus dwellings.

Passivhaus designs should employ "professional planning", such as relevant orientation, shading and ventilation, to overcome a summer overheating risk [4]. There are a number of design approaches to mitigating the risk of overheating in dwellings, such as shading devices, reflective surfaces and thermal mass, that have received a good deal of research attention. For instance, Orme, Palmer and Irving [7] concluded that night time purging was the most effective single intervention to reduce overheating. Tillson et al. [8] showed that using a combination of window shutters or overhangs and ventilation can greatly reduce overheating. Mavrogianni et al. [9] investigated the effectiveness of thermal mass and insulation in reducing overheating. Piccolo and Simone [10] used reflective electrochromic glazing to minimize the solar heat gain and Robinson and Haldi [11,12] and Bennet et al. [13] focused on behavioural interventions to reduce overheating.

The present study has investigated the less examined arrangement by which dwellings have geometric forms that make the south-facing façades self-shading. This paper examines the potential benefits of using different self-shading façade geometries to reduce thermal discomfort in Passivhaus standard dwellings for current and future UK climate scenarios.

\subsection{Future Climate, UK Passivhaus Dwellings and Overheating Risk}

The probable impact of climate change over the coming decades demands two main responses: (i) mitigation of carbon emissions; and (ii) adaptation of buildings to be comfortable in the future climate [14] Adapting to the negative impact of climate change is becoming as important as mitigating the climate change itself [15]. The Intergovernmental Panel on Climate Change (IPCC) [16] stated that, even in the most optimistic projection, the Earth will experience at least $1.8^{\circ} \mathrm{C}$ global average surface warming by the end of the 21 st century. A warmer summer time is estimated to effect energy use patterns and comfort conditions in UK dwellings.

It has been argued that highly insulated and very airtight homes are more prone to overheating than older traditional housing [17-19]. Probabilistic climate change data from UK Climate Change Projections (UKCP09) [20] suggest that the UK will experience hotter and more extreme summers in the coming decades and the risk of buildings overheating may become very significant in future climate scenarios.

\subsection{Definition of Thermal Discomfort (Overheating)}

The definition of the term overheating is defined differently by different groups and it remains an area of uncertainty. The Housing Health and Safety Rating System from the Housing Act 2004 [21] stated " $a$ healthy indoor temperature is around $21{ }^{\circ} \mathrm{C}$. As temperatures rise, thermal stress increases, initially triggering the body's defence mechanisms such as sweating. High temperatures can increase 
cardiovascular strain and trauma, and where temperatures exceed $25^{\circ} \mathrm{C}$, mortality increases and there is an increase in strokes. Dehydration is a problem primarily for the elderly and the very young".

As stated in Section 1.1, for the UK climate a Passivhaus is permitted to use $15 \mathrm{kWh} / \mathrm{m}^{2}$ year to provide space heating to obtain thermal comfort. However, with the potential growth in summer temperature in places like London active cooling may become inevitable to maintain the temperature around $25^{\circ} \mathrm{C}$. Bearing in mind that space heating may decrease because of less severe winters, future criteria may suggest that the limit of $15 \mathrm{kWh} / \mathrm{m}^{2}$ applies for space conditioning including both heating and cooling demand to keep future Passivhaus within the $20-25{ }^{\circ} \mathrm{C}$ optimal temperature for a whole year. CIBSE Guide A [22] defines summer comfort air temperatures for living rooms and bedrooms in UK dwellings as being when indoor temperature are around $23{ }^{\circ} \mathrm{C}$ to $25{ }^{\circ} \mathrm{C}$. The Guide noted that the quality of sleep begins to deteriorate if indoor bedroom air temperatures much exceed $24{ }^{\circ} \mathrm{C}$. To avoid the risk of overheating CIBSE Guide A states that temperature should not exceed $25^{\circ} \mathrm{C}$ for more than $10 \%$ of total occupied hours for living spaces. Inside temperature also should not exceed $26{ }^{\circ} \mathrm{C}$ for bedrooms and $28{ }^{\circ} \mathrm{C}$ for living rooms for more than $1 \%$ of total occupied hours. However, one shortcoming of these so called static criteria is that there is no specific limitation for the severity of overheating-for instance, $1 \mathrm{~h}$ at $28.1^{\circ} \mathrm{C}$ and $1 \mathrm{~h}$ at $32{ }^{\circ} \mathrm{C}$ is considered as $1 \mathrm{~h}$ above $28{ }^{\circ} \mathrm{C}$ with the same level of overheating discomfort. Another concern over static criteria is that they do not include individual adaptation to changing temperatures. Adaptive thermal comfort was developed based on the hypothesis that people in different climate zones prefer different indoor temperatures [23]. The performance of a Passivhaus design is assessed using the Passive House Planning Package (PHPP), which is a set of over 30 linked Excel spreadsheets. In the PHPP spreadsheets overheating hours are calculated for the occupied period when in the living areas temperatures exceed $25^{\circ} \mathrm{C}$. The kitchen is excluded because of the probability of miscalculation of overheating when catering equipment is being operating during occupied periods. Passivhaus tries to keep inside temperatures within the interval of 20 to $25{ }^{\circ} \mathrm{C}$ during whole cycle of the year. There is a limit of $10 \%$ occupied hours having temperatures above $25{ }^{\circ} \mathrm{C}$. For some other criteria a temperature excess of over $25{ }^{\circ} \mathrm{C}$ for up to $5 \%$ of the year is allowed [24].

In reality individuals will adapt to changing climate, therefore, adaptive methods may be more applicable for assessing future indoor thermal comfort. However, static criteria are used mainly for assessing model prediction and whole years of data [9]. Static criteria are also useful to focus and measure one specific parameter or a single design intervention and its impact on indoor thermal behaviour and to give a general prediction on the future possibilities. Whereas adaptive methods take into account all the individual measures assigned to different persons' comfort perception, static criteria are useful for ranking the occurrence of elevated room temperatures but it cannot clearly indicate whether the measured temperature is acceptable or not. People may adapt to the higher temperature (acclimatization) or people may expect higher levels of comfort and a cooler summer temperature as a result of increasing disposable income and higher life quality expectations. For this study the CIBSE Guide A static criteria were used for assessing thermal comfort for alternative climate scenarios. The occupant window opening patterns and the amount of natural ventilation was kept constant for current and future climate conditions in order to make a valid comparison between the façade alternatives. However, it is well understood that occupants will change their behaviour as outside temperatures change and adaptive criteria needs to be analysed for assessing overheating risk for future warming 
climates. However, using constant, i.e., static criteria helped to make a fair comparison to study the impact of a single design factor, i.e., façade geometry.

\subsection{Aims and Objectives}

This study set out to investigate the effectiveness of building geometry as an environmental design criterion. The first objective was to evaluate the impact of future weather data on the Passivhaus structures in order to estimate future overheating risk and rate. The second objective was to introduce self-shading façades as one the adaptation strategies for reducing overheating in homes.

\section{Methodology}

The main method used for this study was computer simulation modelling as a substitute for direct measurement and experimentation. Software reliability and the accuracy of the model were tested against an available real data series. An existing Passivhaus dwelling with available thermal analysis and monitoring data was considered as a reference case to validate the software. Thus, a pilot unit was modelled using the specifications of the reference case. A sensitivity analysis approach on the pilot model was then adopted to assess geometric alterations to the Passivhaus south facade. Eight preliminary steps were taken to examine the impact of the tilted south façade on Passivhaus performance and comfort:

i. Selection of an existing Passivhaus dwelling in the UK

ii. Modelling and validation of the dwelling's performance

iii. Conducting an initial pilot study

iv. Selecting weather data for simulation

v. Defining the risk of overheating

vi. Selecting the effective façade geometry (tilt angle)

vii. Implementing the effective design to current and future weather conditions

viii. Assessing the impact of the introduced geometry to future performance of the Passivhaus

\subsection{Reference Case}

An existing nearly zero carbon UK Passivhaus dwelling, Larch House in Ebbw Vale, Wales (Figure 1) with a typical cube-shape and large south-facing glazing (55\% glazing of the façade area) was chosen as the reference case. It achieved an outstanding draught-free construction with an air tightness result of 0.2 air changes per hour $(\mathrm{ac} / \mathrm{h})$ at 50 Pascal indoor-outdoor pressure difference. The building uses external roller blinds to prevent summer overheating. It should be noted that the blinds have been assumed to be operated by the occupants in the summer time.

Occupant Behaviour

Occupant behaviour, such as operating windows and blinds, can have an influential impact on the energy performance of a house [17,25,26]. Findings from the monitored performance of the first London Passivhaus dwelling (Camden Passivhaus) [27] reported that occupants did not intend to change their window opening and blind operation use in future from the monitored data, which suggested that temperatures were above the CIBSE thermal comfort criteria in several periods. It has also been 
observed that the occupants of Larch House do not use the blinds to their best advantage [28]. Large glazing areas could lead to overheating in summer if internal/external blinds are not operated optimally. In the majority of Passivhaus dwellings, including Larch House, shading is controlled by internal or external blinds, which require occupant attention and understanding. Robinson and Haldi [11,12] showed how occupants' behaviours in terms of controlling windows and blinds can make a difference to the frequency of overheating.

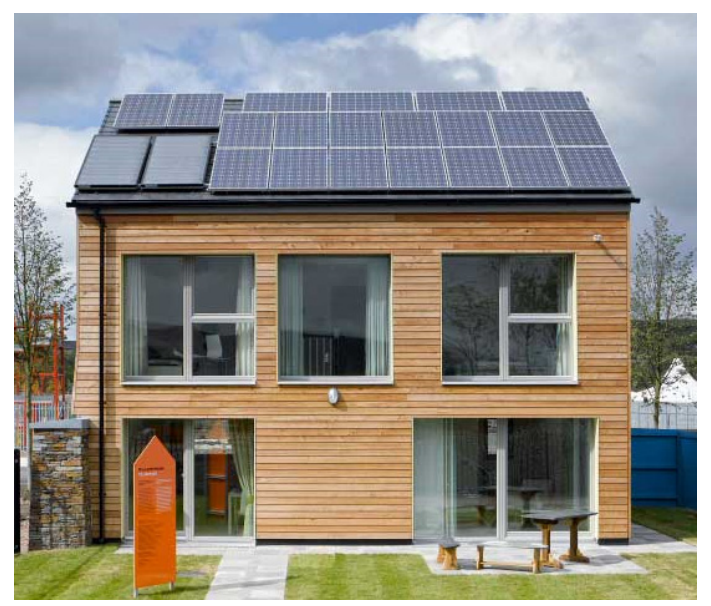

Figure 1. Larch House in Ebbw Vale.

\subsection{Modelling and Validation}

The building was modelled using the dynamic thermal simulation package DesignBuilder (integrated EnergyPlus engine) version 3.4 [29]. DesignBuilder has been validated by reliable energy calculation standards, i.e., EN ISO 13790 Standards [30], ASHRAE [31], and EnergyPlus validation testing results [32] that verified the robustness of the software. However, to ensure confidence in the results of the DesignBuilder model, it was necessary to compare the simulation data with the values provided by the designers. Bere Architects used the steady state Passive House Planning Package (PHPP) for simulation of the house. The predicted results from the PHPP file were used to validate the model. Monitoring data from the Technology Strategy Board [17] were also used for verifying the simulation data and mark out unexpected occupant's behaviour.

Post occupancy monitoring and evaluation of a building helps to compare the actual and predicted performance and to observe if any significant "performance gap" has been experienced. What is significant about monitoring compared to modelling is that unexpected occupant behaviour can be identified. Differences between the predicted and actual performance of low energy dwellings can be significant in some cases [33]. A comparison of the monitored and modelled data for Larch House (see Table 1) showed a small percentage difference for annual heating demand and air tightness. However, monitored data highly exceeded the total energy demand calculated by PHPP. Additional energy demand to the predictions occurred due to the higher amount of cooking and electricity consumption from sockets (appliance consumption type). The typical (conventional) UK domestic electricity consumption is around $3300 \mathrm{kWh}$ per annum; for Larch House PHPP predicted an electricity consumption of $2209 \mathrm{kWh}$, whereas the actual monitored data revealed a value of $4495 \mathrm{kWh}$ (see Table 2). 
Table 1. Data comparison between PHPP, monitored data and DesignBuilder simulation results.

\begin{tabular}{ccccc}
\hline Measures & PHPP & Monitored data & DB.1 & DB.2 \\
\hline Annual heating demand $\left(\mathrm{kWh} / \mathrm{m}^{2}\right.$ year $)$ & 13 & 9.3 & 9.1 & 13.5 \\
Total Energy requirement including heating $\left(\mathrm{kWh} / \mathrm{m}^{2}\right.$ year $)$ & 83 & 189 & 166 & 96 \\
Airtightness $\left(\mathrm{h}^{-1}\right.$ at $\left.50 \mathrm{~Pa}\right)$ & 0.2 & 0.198 & 0.2 & 0.2 \\
Annual $\mathrm{CO}_{2}$ emission $\left(\mathrm{kg} \mathrm{CO} / \mathrm{m}^{2}\right.$ year $)$ & 20.1 & 35.6 & 34.2 & 26.2 \\
Frequency of overheating $T>25^{\circ} \mathrm{C},(\%)$ & $6 \%$ & $34.9 \%$ & $33.1 \%$ & $17.5 \%$ \\
\hline
\end{tabular}

Table 2. Annual average electricity use from two years of Larch House monitoring.

\begin{tabular}{cc}
\hline Measured (kWh) & Larch House \\
\hline Lights & 245 \\
Cooking & 660 \\
Sockets & 3002 \\
Total electricity (PV offset not included) & $\mathbf{4 4 9 5}$ \\
\hline
\end{tabular}

Data from the monitoring also showed that the house did experience an overheating frequency (internal temperature exceeded $25^{\circ} \mathrm{C}$ ) for over $34 \%$ of total occupied hours in the main living space. This high percentage of overheating was mainly because occupants did not open the windows in summer. The monitoring revealed that in summer the children did not want windows to be open at night due to a fear of spiders. Although this could be resolved by fitting insect mesh in the window, the impact of summer night purge cooling should be incorporated into calculations by increasing the ventilation rate from the monitoring value. There was a small difference between the DesignBuilder model (herby referred to as DB.1) and the monitoring data but a much bigger difference with the results from the PHPP prediction. After the above mentioned unexpected occupants' behaviour was resolved and explained to the occupants, a second set of simulations (herby referred to as DB.2), with adequate natural ventilation and typical electricity use, were conducted. This will help to avoid exaggerated overheating in future climate analyses (after installing insect mesh the house continues to be monitored and it is expected that the overheating rate of the first two years of monitoring will be reduced [34]). In addition to the Passivhaus requirements, Larch House has a photovoltaic PV system installed to meet Level 6 of the at-the-time applicable UK Code for Sustainable Homes, i.e., zero carbon emission. PHPP calculated $20.1 \mathrm{~kg} / \mathrm{m}^{2} \mathrm{CO}_{2}$ emissions for the building, with $12.8 \mathrm{~kg} / \mathrm{m}^{2} \mathrm{CO}_{2}$ emissions being avoided due to the solar system. However, the building did not achieve a truly net zero carbon emission and required a PV system of approximately $6 \mathrm{~kW}$ peak to meet zero carbon emissions. This study gives the value of the building's total consumption rather that net value of the measures, i.e., this study ignored the $\mathrm{CO}_{2}$ emission avoided due to the solar panels and electricity usage offset by the solar system. In this way the consumption of the dwelling can be assessed based on the building characteristics and not the power of the PV system.

As a result of comparing the Larch House monitored data with DesignBuilder predictions, and then fine tuning the DesignBuilder parameters to reflect known conditions in the house, it was felt that a satisfactory protocol had been established for using DesignBuilder in the next stage of this study's analysis of façade geometry impacts on overheating. 


\subsection{Pilot Study}

To the best knowledge of the authors, the impact of a tilted façade has not been studied in terms of thermal comfort and energy use for a Passivhaus design. In order to gain a better initial understanding of the environmental parameters and the impact of the external inclination geometry, the preliminary pilot study modelled a simple single thermal zone in the form of a box shape replica of a house. The pilot study was, in fact, conducted to examine the effectiveness of the software in response to changing the façade inclination.

A hypothetical Passivhaus standard unit in a suburban exposure was developed to represent a typical Passivhaus dwelling (Figure 2). The unit was nine metres long, seven metres wide and three metres high and was a stand-alone unit. Construction materials, building specifications and occupancy schedule were set to be similar to the Larch House case study. The inclination angle $\theta$ of the south facade was manipulated to test the effectiveness of the façade inclination at $5^{\circ}$ intervals starting from $\theta=90^{\circ}$, i.e., a vertical façade, to $140^{\circ}$, i.e., $50^{\circ}$ beyond the vertical, as shown in Figure 3. The input data such as $U$-values, HVAC system, schedule pattern, and glazing area were chosen based on the original Larch House PHPP file [35] to generate the closest interpretable results. Table 3 indicates the building fabric thermal characteristics used for the model. The amount of glazing was based on window-to-wall ratio (WWR) and was applied to the pilot study model to represent 53\%, 11\%, 7\% and $0 \%$ for south, east, north and west facing facades respectively. Figure 2 also depicts the amount of south glazing, including fixed and opening windows. Similar to the case study, external roller blinds were provided to try and prevent summer overheating.

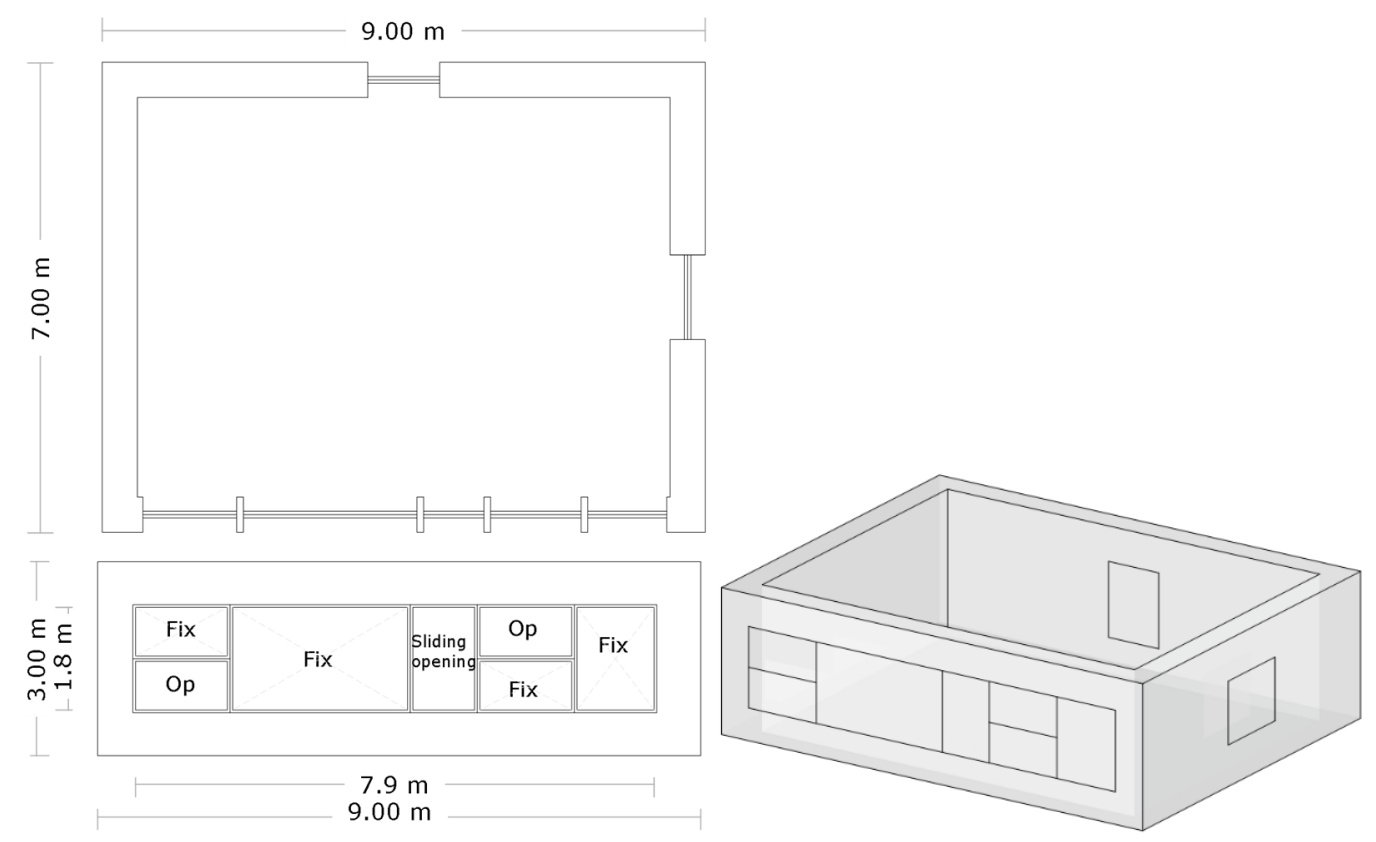

Figure 2. Pilot unit.
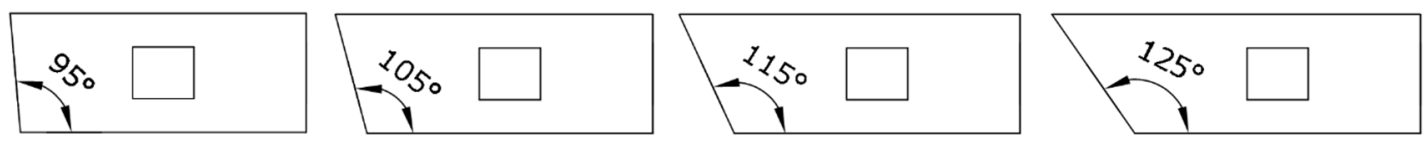

Figure 3. Side elevation of different façade inclinations. 
Table 3. $U$-Values used in the pilot study model.

\begin{tabular}{ccc}
\hline Element & $\boldsymbol{U}$-Value $\left(\mathbf{W} / \mathbf{m}^{\mathbf{2}} \mathbf{K}\right)$ & Thickness $(\mathbf{m m})$ \\
\hline Exterior walls & 0.095 & 467 \\
Flat roof & 0.074 & 578 \\
Ground floor slab & 0.076 & 800 \\
Windows & 0.860 & Triple glazing $13 \mathrm{~mm}$ argon-filled \\
\hline
\end{tabular}

The HVAC operation template for the thermal simulation was set to mechanical ventilation with heat recovery system (MVHR). It must be noted that, similar to the existing reference case, the heat recovery system and heating supply were ON for winter time as the Passivhaus provides most of its heating demand from the heat recovery system, i.e., heat given off by appliances, occupants and solar gain. However, in order to maintain a minimum indoor air temperature of $20{ }^{\circ} \mathrm{C}$ on the coldest days a small amount of supplementary heating is required, which is provided in the form of a post-air heating unit in the MVHR system. Any additional heating is acceptable up to $15 \mathrm{kWh} / \mathrm{m}^{2}$ year [5]. For the summer period natural ventilation was set to be operating, while the cooling supply was OFF since there is no mechanical cooling device used in the reference Passivhaus case. The blind operation schedule was set to simulate a typical use where occupants operate the blind based on the UK weekdays, weekends and holidays. This was chosen from a compact schedule script in the DesignBuilder library specified for living areas, where the fraction of the blind operation is higher during intensive summer sunshine hours. However, this does not mean that blinds were always closed during these periods. Natural ventilation was assumed to be operating in summer by opening the windows (cross ventilation). The air change rate for summer was $0.8 \mathrm{ach}$. In winter windows were closed and mechanical ventilation with a minimum 0.3 ach was operating. Heating and cooling set points were 20 and $25^{\circ} \mathrm{C}$ respectively and the efficiency of heat recovery was set to $87 \%$ ๆ $\mathrm{HR}$.

\subsection{Weather Data for Simulation}

The most recent future climate change predictions for the UK were provided by UK Climate Projections in 2009 (UKCP09). The probabilistic weather data presented in UKCP2009 were not in a format that could be readily used by building modelling software. Consequently, a study entitled PROMETHEUS, based at Exeter University, developed techniques for creating future weather files using UKCP09 data but in software-friendly formats, such as in Energy Plus format (.epw) [20]. These hourly weather data files were available for medium and high emission scenarios with different percentile probabilities for both Test Reference Year (TRY) and Design Summer Year (DSY) weather data, where DSY tends to give warmer summer days and TRY is more representative of the whole year. The majority of the studies to date have used medium or high emission future weather data with the central estimate $(50 \%)$, while some used the worst case scenario of high emission $90 \%$ probability, where the changes are very unlikely to be greater than the given value. Gupta and Gregg [19] argued that the most robust design for future climate should be resilient to a worst case scenario. On the other hand, some argue $[17,28]$ that considering extreme worst case scenarios for building design is very costly and unnecessary because it is very unlikely to happen. For the modelling in this paper an average pessimistic scenario of high emission 50 percentile probability was chosen rather than the low, medium or worst case scenario. It must be borne in mind that this study tried to obtain an indication of what may happen 
and not to find absolute real values. Obviously, the current Ebbw Vale climate was used to validate the Larch House modelling case study exercise described previously. However, for assessing overheating risk the DesignBuilder modelling used weather files relating to future scenarios in London because London is projected to experience the greatest future external air temperature rises in the UK as a result of both climate change and urban heat island impacts [36].

\section{Results and Discussion}

\subsection{Overheating Risk for the Pilot Study Unit in Current and Future Climates in London}

Figure 4 gives current and future data concerning the consequence of predicted future temperatures on the thermal comfort inside the pilot unit with the typical vertical south façade. The bar chart depicts average monthly outside dry-bulb temperature over a year for current and future climates London. The data illustrate the predictions of possible future temperatures in London under high emission 50 percentile tested reference year (A1Fi 50\%_TRY) for 2030, 2050 and 2080. The horizontal band across Figure 4 shows the range of comfort temperatures.

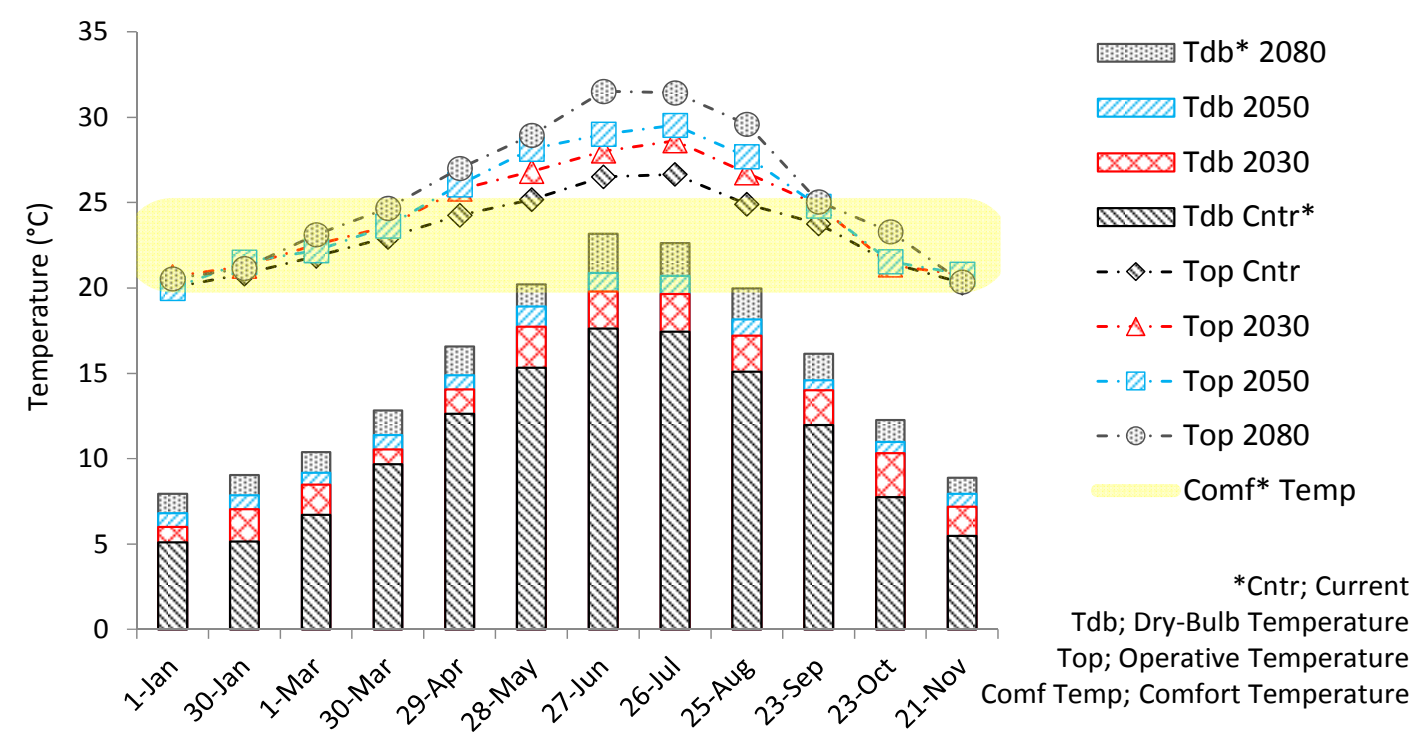

Figure 4. Monthly outdoor dry bulb air and average indoor operative temperature $\left({ }^{\circ} \mathrm{C}\right)$ in the pilot study unit for current and future weather conditions (London).

It is clear from Figure 4 that temperatures will raise over the whole 12 month cycle of the year in future. However, the increases are more significant for the summer time, especially in June and July. The increase in average dry bulb air temperature in summer time is double the temperature rise for winter. The highest average dry bulb temperature for the current CIBSE file London climate is around $17.5^{\circ} \mathrm{C}$, while the value for 2080 shows a dramatic increase to over $23^{\circ} \mathrm{C}$. This will clearly cause an increase in operative temperatures inside the building. The curves in Figure 4 represent the indication of possible future overheating risk for London which needs to be taken into consideration at the early design stage. The mean value for indoor operative temperature never dropped below $20{ }^{\circ} \mathrm{C}$ whilst space heating demand was kept within the limit of the Passivhaus standards for current and future climate. This showed the robust performance of the Passivhaus structure for the heating period. However, the 
temperatures increase to just over the comfort zone in June and July for current weather data. For the current climate the indoor temperature of the super insulated pilot unit is close to an average of $26^{\circ} \mathrm{C}$ in July. However, the future temperatures show a trend of thermal discomfort during summer, where inside temperatures for the hottest month of the year in 2080 may rise up to $31{ }^{\circ} \mathrm{C}$ if no additional adaptation strategies (apart from blinds) were implemented in the Passivhaus design. It should be noted that the window opening pattern and the amount of natural ventilation were kept constant for current and future climate conditions in order to make a valid comparison between the façade alternatives. However, it is accepted that occupants will change their behaviour as outside temperatures change and interiors become more uncomfortable.

\subsection{Effect for the Pilot Study Unit of the Inclined Façade on Heating and Cooling Demand}

Next, the study examined the impact that different façade geometries would have on the energy required (supplementary heating and cooling) to provide the minimum indoor temperature of $20^{\circ} \mathrm{C}$ in winter and a maximum indoor temperature of $25{ }^{\circ} \mathrm{C}$ in summer. The MVHR heating option remained $\mathrm{ON}$, based on a set point of $20^{\circ} \mathrm{C}$. Natural ventilation was operating and the cooling option was switched $\mathrm{ON}$ in order to supply cool air when the temperature rose above the cooling set point of $25^{\circ} \mathrm{C}$. Figure 5 demonstrates the amount of energy, including heating and cooling, that the pilot unit required to keep the temperature within the interval of $20-25^{\circ} \mathrm{C}$ for the London climate under current and future weather conditions. It should be noted that the required supplementary cooling in summer was provided by an air-conditioning system running on electricity.

Results from the pilot study analysis (see Figure 5) showed that the façade inclination angle had a noticeable impact on both annual cooling and heating demand for the Passivhaus pilot unit in London for current and future weather scenarios. The curves compare the heating load for different south façade inclinations. As expected, for the heating demand there was an upward trend as the inclination angle grew. For all climate periods a steeper upward trend was observed when the inclination angle went beyond $115^{\circ}$. The reason for that is, perhaps, that there is some overshadowing during the winter.

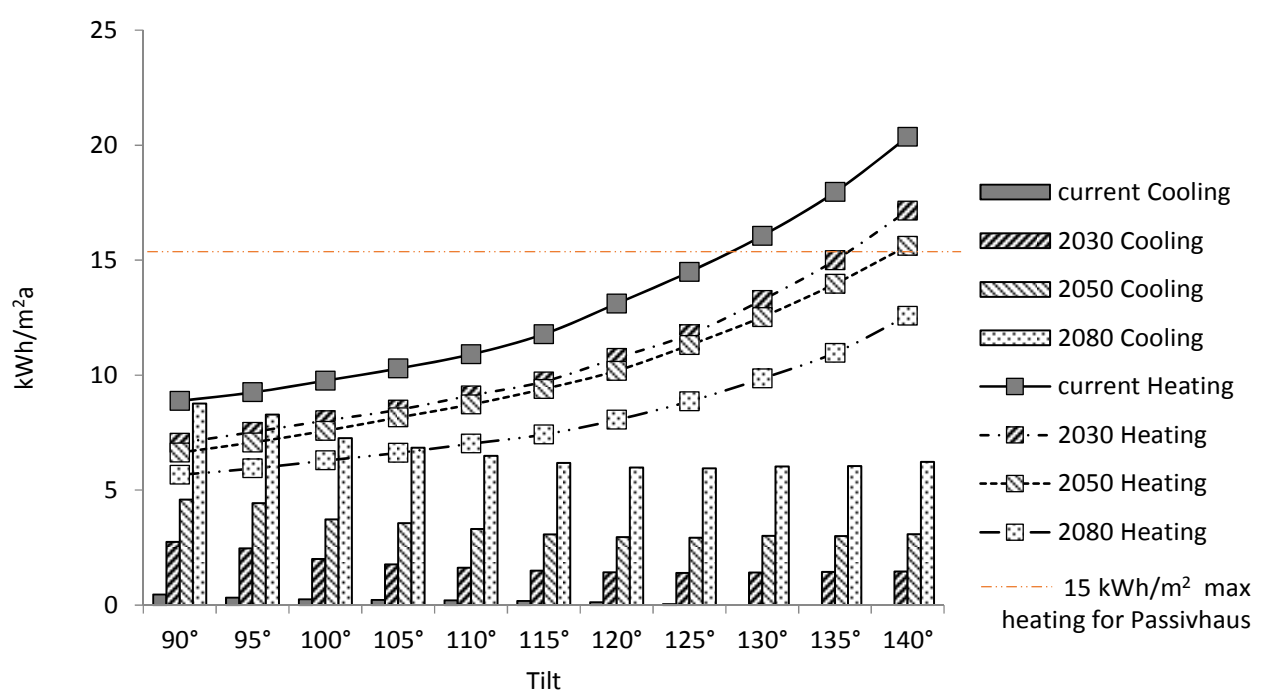

Figure 5. Annual energy demand of the pilot study unit for different façade geometries under four climate scenarios. 
The vertical bars in Figure 5 show current and future data concerning the additional cooling load energy to maintain the maximum set point temperature of $25{ }^{\circ} \mathrm{C}$ during the summer. In contrast to the heating demand, the cooling load decreases as the inclination angle increases away from the vertical. However, the inclination stops having much effect when the angle reaches $120^{\circ}$. What is surprising is that when the angle increases from $130^{\circ}$ to $140^{\circ}$ the cooling demand starts to rise marginally. This might be because the windows on that façade will then receive more reflected radiation from the ground. The software has a surface solar reflectance (albedo) that can be modified between 0 and 1 . In this study the default value of 0.3 was modelled as this value represents a typical average albedo for grass and soil.

It can be seen that there is a modest cooling demand for the current London climate, which can be eliminated by implementing an angled façade (details of corresponding indoor temperature can be found later in Figure 8a). It is clear from the data that the cooling demand will raise significantly by the second half of the century, when the self-shading strategy promises a substantial drop in overheating risk for future climates in London. However, a data analysis of all aspects of energy consumption is required to determine the design of the envelope shape that provides solar access in winter while acting as a self-shading facade in the summer.

The pilot study unit was also tested in a free-running mode, when both cooling and heating were unavailable for simulations. January and July were chosen as being representative of cold and hot months. Figure 6 shows the average operative temperature within the unit for January and July. It is observed that applying the $115^{\circ}$ inclined angle produced an average of $0.5^{\circ} \mathrm{C}$ lower indoor temperature in January while the temperature dropped by an average of $2{ }^{\circ} \mathrm{C}$ in July.

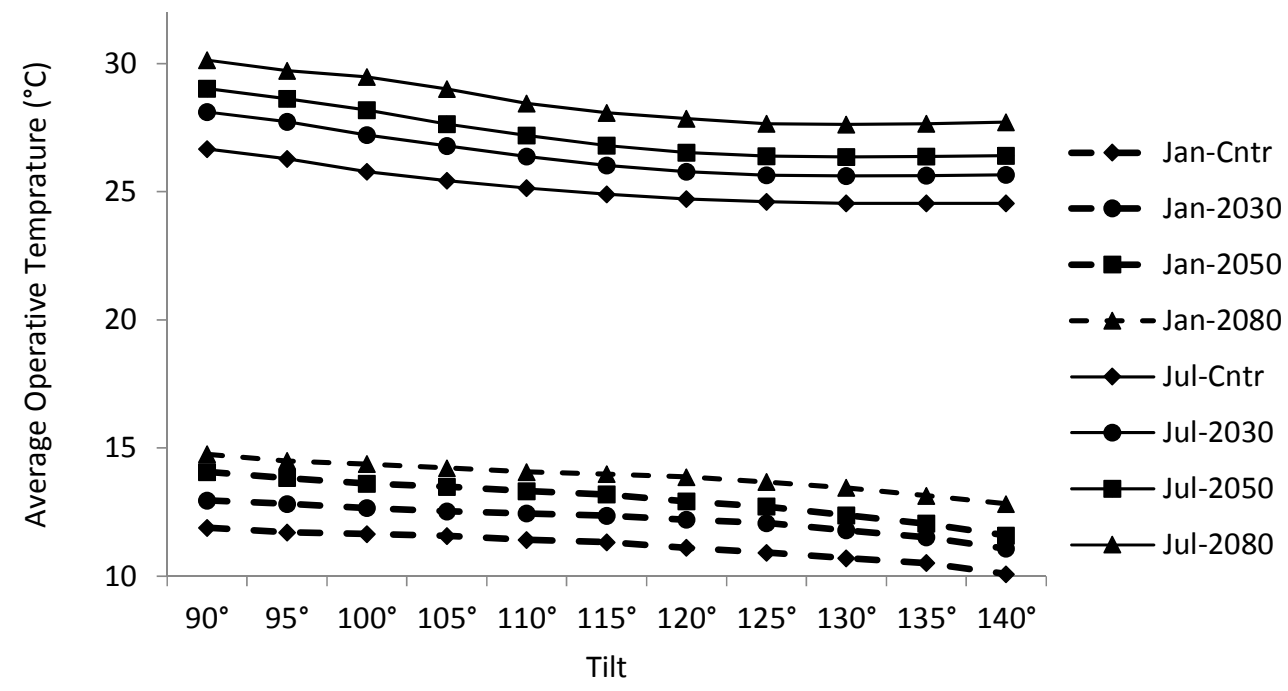

Figure 6. Average indoor operative temperatures for free-running Passivhaus pilot unit in January and July.

\subsection{Overheating Frequency for the Pilot Study Unit}

As mentioned above this study adopted the CIBSE Guide A static criteria on overheating (i.e., temperatures exceeding $25^{\circ} \mathrm{C}$ for more than $10 \%$ and $28{ }^{\circ} \mathrm{C}$ for more than $1 \%$ of total occupied hours) to assess the frequency of overheating in the pilot study unit. Figure 7 shows annual overheating rates for the four climate periods based on the number of hours at which the interior air temperature exceeded $28{ }^{\circ} \mathrm{C}$. 
Applying an inclined facade should be precisely calculated to avoid overshading. The curves in Figure 5 showed that, upon implementing a tilted façade, the heating demand increased as a consequence of reduced direct solar radiation gain. According to the data, applying a tilted wall could be beneficial in reducing the potential overheating for current and future climates. Figures 5-7 suggest that in order to eliminate current overheating and reduce future overheating without greatly compromising the space heating demand then a reasonable inclination angle for the façade would be around $115^{\circ}$.

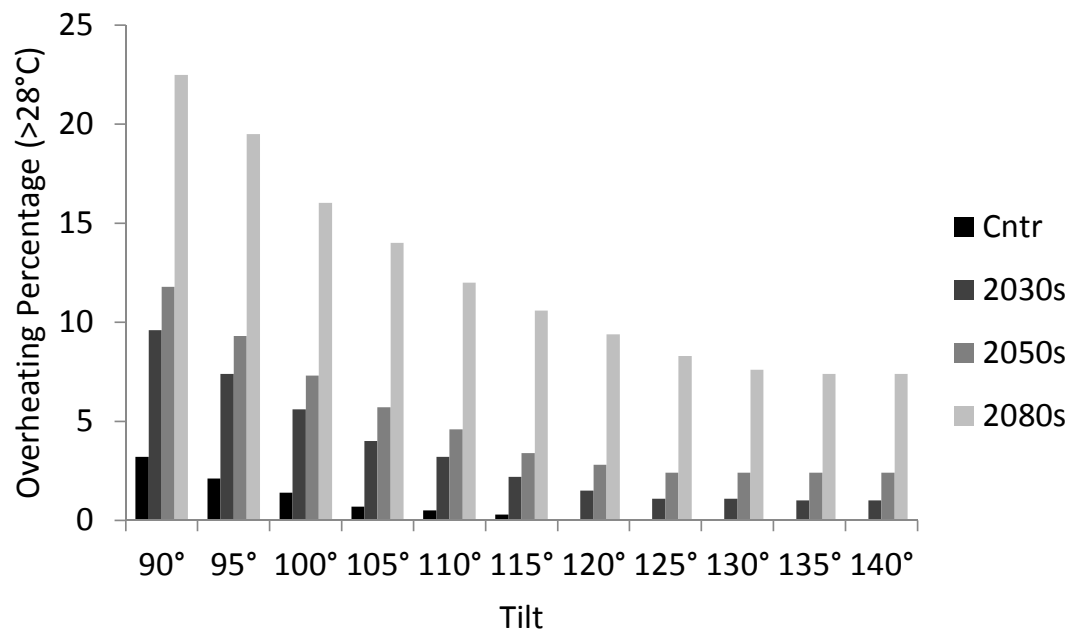

Figure 7. Frequency of overheating in the pilot study unit percentage of occupied hours the indoor operative temperatures exceeds $28^{\circ} \mathrm{C}$.

\subsection{Implementing for the Pilot Study Unit the Effective Façade Geometry to Current and Future Conditions}

Following on from the data analysis on the pilot study, the vertical south façade of the pilot study unit was replaced by a tilted façade with a $115^{\circ}$ inclination. The simulations were carried out using the London future weather files. As the modelled data showed, there was a significant drop in summer operative temperature when using a $115^{\circ}$ tilted wall, whereas the operative temperature did not significantly drop in winter. The implementation of a steeper façade, on the other hand, will block the required solar gain in winter while an angle around $115^{\circ}$ will guarantee solar heat in winter and obstruct the high solar irradiation on hot summer days. Figures 8 and 9 indicate the annual monthly mean operative temperatures for heating (Figure 8) and cooling (Figure 9) demand when comparing the vertical $\left(\theta=90^{\circ}\right)$ and the suggested tilted façade $\left(\theta=115^{\circ}\right)$. The line graphs indicate operative temperature of the pilot unit with vertical and tilted south façades for current and future climate predictions. The bar charts indicate the amount of heating and cooling needed to provide comfortable temperature, i.e., indoor temperatures between 20 and $25^{\circ} \mathrm{C}$. As mentioned earlier, Passivhaus, due to its super insulation, is capable of maintaining an internal temperature of $20{ }^{\circ} \mathrm{C}$. The heat recovery system also operates by utilizing the heat given off by appliances, occupants and solar gain. However, a small amount of supplementary heating was required during the coldest period of the year (Figure 8). With the vertical glazed façade in the south elevation the pilot study unit experienced a marginal summer overheating rate under current climate conditions. Therefore, to ensure a comfortable indoor environment, the unit required a small proportion of supplementary cooling. This need was eliminated 
by implementing the tilted façade of $115^{\circ}$ (Figure $9 \mathrm{a}$ ). For the climate periods of the $2030 \mathrm{~s}$ and $2050 \mathrm{~s}$ the building experienced over $9 \%$ and $11 \%$ overheating respectively, exceeding significantly the $1 \%$ benchmark limit. This was reduced by the self-shading façade to just over $2 \%$ and $3 \%$ for the 2030 s and 2050s climate periods respectively (Figure 9b,c). By the end of the century overheating is expected to occur in shoulder seasons, when high indoor temperatures could be seen from May up to September in the 2080s. Supplementary cooling for the Passivhaus pilot study unit with a vertical, highly glazed façade leapt to the point where the electricity consumption for summer cooling just surpassed the energy demand for space heating. Introducing an angled façade, however, cut the amount of supplementary cooling by up to $50 \%$ (Figure $9 \mathrm{~d}$ ), whereas the energy consumption for heating climbed only marginally, ensuring it did not exceed the maximum energy demand requirement of the Passivhaus standards. Overall, the current climate overheating risk of $3.2 \%$ was eliminated to below the benchmark number of $1 \%$. For future weather projections the overheating rate was significantly reduced by the angled façade. However, the angled facade did not completely eliminate the potential overheating risk, especially for the climate of the 2080 s.

\section{Effect of the Inclined Façade on Daylighting}

While shading strategies are among the tools to reduce overheating and glare discomfort, they can form as an obstacle to prevent good daylighting. The optimal design of any shading system requires an adequate trade-off between visual and thermal comfort. Much has been written about optimizing the functionality of external shading devices from different viewpoint [37-39], but none of them analyzed the impact of the façade inclination on the indoor illuminance for a relatively small house. This study was not focused on the daylighting performance of a Passivhaus. However, it is interesting to understand the consequence of the façade inclination and so a simplified numerical analysis was undertaken to show the effect inclination has on overall daylighting illuminance. The DesignBuilder package includes the advanced lighting simulation software Radiance, which provides the detailed calculation of illuminance data, including average daylight factor for each zone. Due to the large number of variables a relatively simple daylighting analysis on the pilot unit with different façade alternatives was examined. The results were generated based on BREEAM credit HEA1 with CIE overcast day (10,000 Lux). The maximum grid size and complexity of the chosen template type will significantly affect the time taken for the calculations. Therefore, a template type of "Good" with no interpolation (refer to [40]) with the default grid size was chosen. Since the pilot study was not divided into different zones by internal partitions the results may vary noticeably compared with actual cases. However, this analysis was not trying to obtain the accurate values of illuminance in the unit but attempting to understand the significance of inclination on daylighting illuminance. Figure 10 reveals the consequence of a tilted façade on the average daylight factor in a zone. Using a tilted façade of $115^{\circ}$ will reduce the daylight factor by approximately $44 \%$ considering the current London climate. It may also increase the need for artificial lighting. It is worth mentioning that some of the decrease might be of benefit for visual comfort by blocking some of the direct glare. In addition, other, more traditional shading strategies are also likely to decrease daylighting levels. 

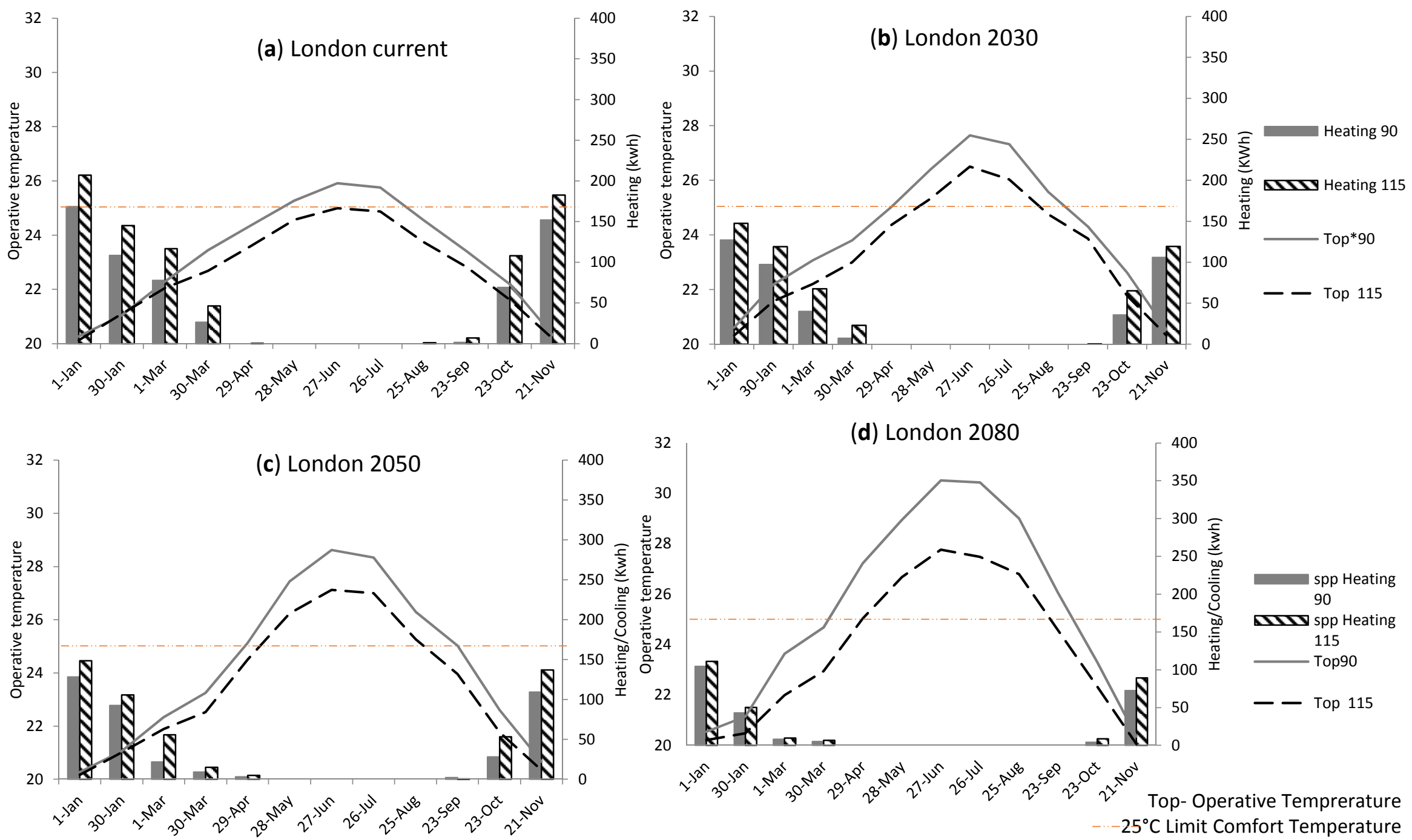

Figure 8. Indoor temperature and monthly supplementary heating required for the unit with vertical and tilt facade under four climatic periods. 

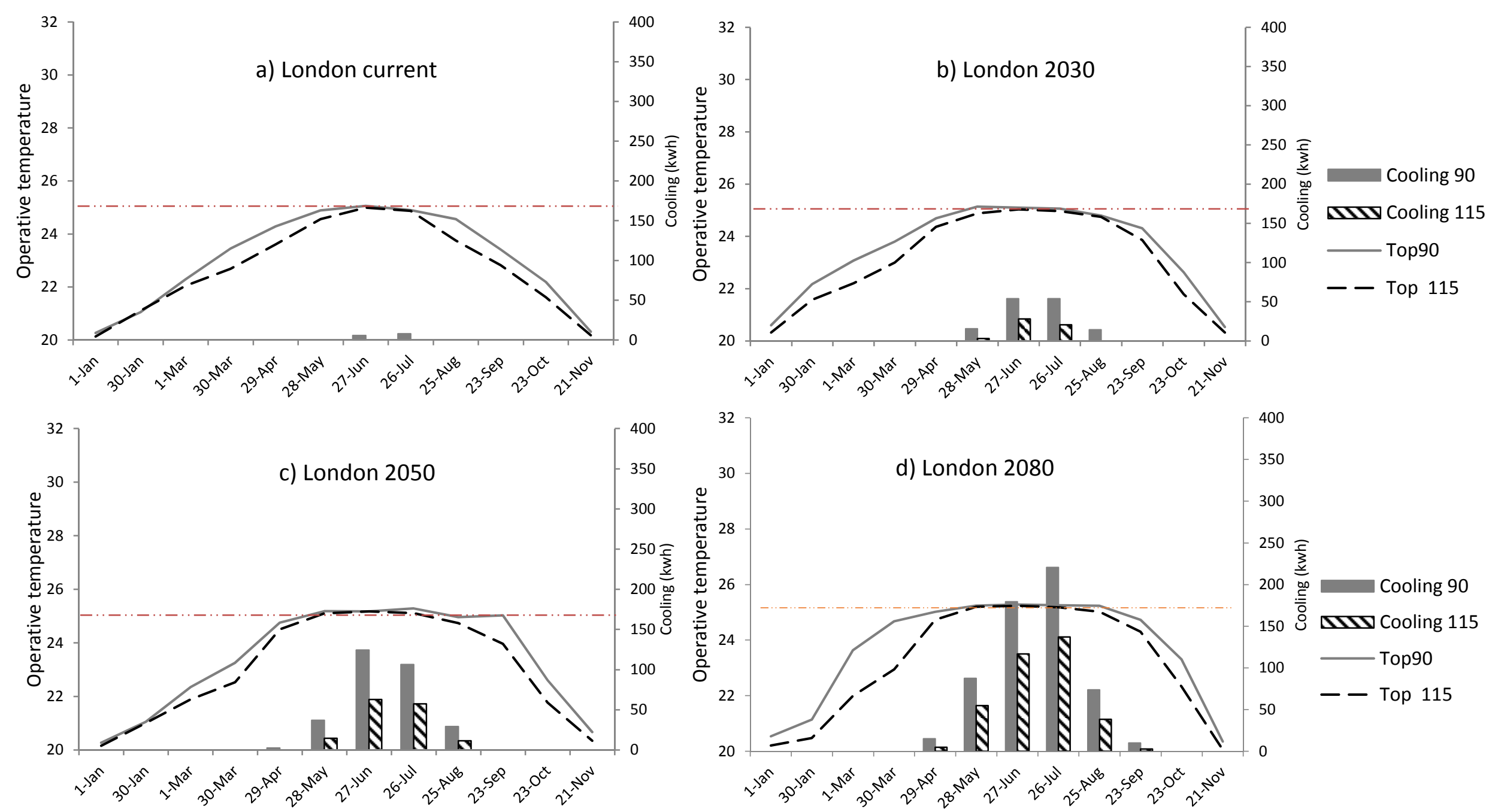

Figure 9. Monthly cooling required for the unit with vertical and tilted facade under four climatic periods. 


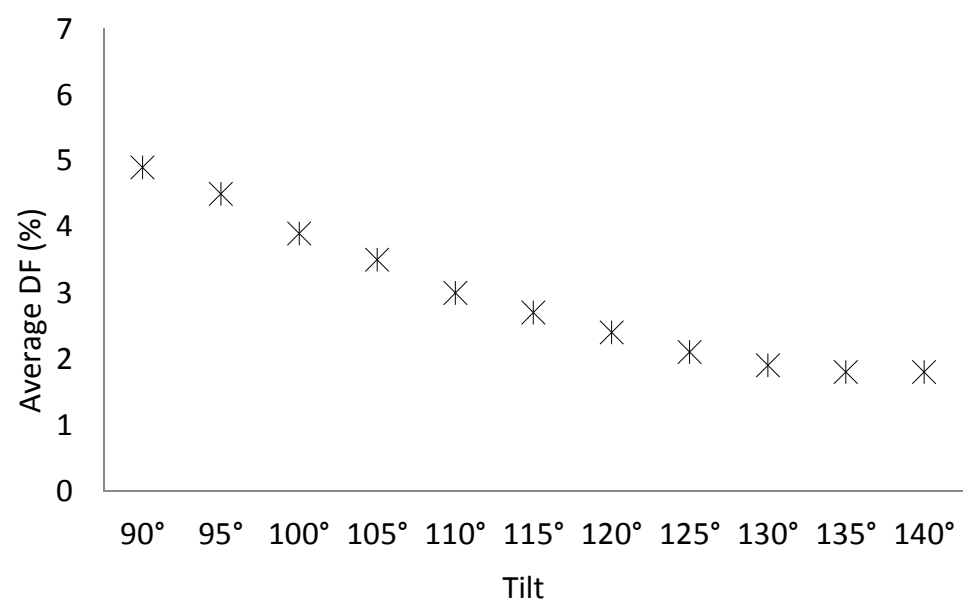

Figure 10. Average daylight factor in the whole unit with different façade inclinations.

\section{Discussion and Future Studies}

This is clear that when building a house with an angled facade there are some consequences in terms of structure, ventilation, daylighting and overall cost of the building. However any intervention will have a particular consequence on these issues. The cost of interventions will vary significantly. There is not a clear fixed price source to provide information that covers all the studied interventions. However, a report from Energy Saving Trust [41] estimated the cost of some intervention. Envelope insulation is by far the highest cost among the interventions. Triple windows and external shutters, internal blinds and fixed shading devise were the medium cost options. Night ventilation was among the cheapest interventions to tackle overheating in the UK. However, this will require the window security upgrade [42].

When the façade inclination increases the total surface area increases. This will increase the surface area exposed to outdoor temperature and consequently increase the heat loss. On the other hand the volume of the interior expands but the land cover will remain the same as a vertical façade and the extra overhang space can be used as a balcony for the upper floor without increasing the footprint of the property.

The effect of self-shading facade on the wind flow pattern around and inside the building also will vary from the vertical wall or having other shading devices such as overhang. This will be studied in a separate paper to provide detailed information about the fluid dynamics of the air movement and the amount of natural ventilation will be investigated respectively. Although the impact of the tilt facade on daylighting was briefly mentioned, a detailed analysis on the illuminance levels for different facade inclinations and also other shading devices will be conducted in a separate paper. Another issue which is worth investigating is the geography. Assuming a tilted wall in London could minimize overheating for future climates, but not eradicate totally the overheating, it would be interesting to know if the same façade tilt angle could completely remove overheating in future climates or if a steep angle would increase heating demand in a cooler climate at a different location and latitude.

\section{Conclusions}

The study has investigated the overheating risk in a UK Passivhaus and examined a novel way to reduce that risk for future climate scenarios. The study tested the high medium scenario (still not the 
worst case scenario), and the risk of overheating appeared to be significant. Some good examples of adaptive innervations were reviewed within the literature of the study and a proposed strategy was tested to define whether this can be counted as a successful intervention towards reducing the negative impact of the warming climate.

Some shading strategies addressed in the literature have limitations-for instance, occupants may not use blinds in the optimum way, thus reducing their effectiveness in combating overheating. This paper presented dynamic thermal simulations on a pilot study Passivhaus detached house unit. The study summarised how one factor could be considered in design stage to be best adapted to reduce future negative impacts of climate change and withstand current requirements. It was concluded that geometric considerations would help to improve the resilience of the London domestic stock to a warming climate and reduce reliance on the potential installation of air conditioning systems. It was found that a self-shading strategy via a $115^{\circ}$ tilted south façade in London could eliminate the current climate overheating risk and mitigate greatly the future overheating risk. However, it was found that further interventions, like enhancing natural ventilation, will be necessary to minimize discomfort thermal condition within a Passivhaus dwelling. However, the proposed method tries to demote the overheating risk from high to medium or slight risk. Further energy efficiency programmes need to include adaptation if the adverse effects of summer overheating are to be avoided in the future. The results tend to emphasize the effectiveness of a good shading strategy in adapting dwellings to higher summer temperatures. Although London was chosen for the detailed analysis, the proposed approach could be applied to other locations to test how latitude and climate impact on the preferred façade tilt angle.

\section{Acknowledgments}

The authors would like to thank Justin Bere of Bere Architects for providing valuable advice and useful data regarding the case study (Larch House). The authors also wish to thank United Welsh Housing Association for their support and information. The authors wish to express their thanks to Ian Ridley for advising on the monitoring data.

\section{Author Contributions}

The paper investigated on the question; is there a relationship between the architectural form, energy usage and overheating risk in Passivhaus dwellings? The study used a tilted façade as a shading device to avoid summer overheating risk. It was found that inclined façade could potentially act as a fixed shading device and reduce overheating.

\section{Conflicts of Interest}

The authors declare no conflict of interest.

\section{References}

1. The Climate Change Act. Available online: http:/www.legislation.gov.uk/ (accessed on 23 January 2015). 
2. James, C.; David, M.; Geoff, S.; Penny, J.; Ben, B.; Kate, B.; Robin, B. UK Climate Projections Science Report; Met Office Hadley Centre: Exeter, UK, 2010.

3. Kym, M.; Brylewski, R. Passivhaus Primer: Introduction an Aid to Understanding the Key Principles of the Passivhaus Standard; BRE Trust: Watford, UK, 2010.

4. Passipedia - The Passive House Resource. The Passivhaus Institute: Darmstadt, Germany. Available online: http://passipedia.passiv.de/passipedia_en/basic/Summer (accessed on 23 January 2015).

5. McLeod, R.; Mead, K.; Standen, M. Passivhaus Primer: Designer's Guide: A Guide for the Design Team and Local Authorities; BRE Trust: Watford, UK, 2010.

6. Feist, W. Passive House Planning Package Version 7; Darmstadt: Rheinstrabe, Germany, 2012.

7. Orme, M.; Palmer, J.; Irving, S. Control of Overheating in Well-Insulated Housing. In Building Sustainability: Value and Profit; CIBSE: London, UK, 2003.

8. Tillson, A.-A.; Oreszczyn, T.; Palmer, J. Assessing impacts of summertime overheating: Some adaptation strategies. Build. Res. Inf. 2013, 41, 652-661.

9. Mavrogianni, A.; Wilkinson, P.; Davies, M.; Biddulph, P.; Oikonomou, E. Building characteristics as determinants of propensity to high indoor summer temperatures in London dwellings. Build. Environ. 2012, 55, 117-130.

10. Piccolo, A.; Simone, F. Effect of switchable glazing on discomfort glare from windows. Build. Environ. 2009, 44, 1171-1180.

11. Haldi, F.; Robinson, D. Modelling Occupants' Presence and Behaviour-Part II. J. Build. Perform. Simul. 2011, 5, 1-3.

12. Robinson, D.; Haldi, F. Modelling Occupants' Presence and Behaviour-Part I. J. Build. Perform. Simul. 2011, 4, 301-302.

13. Bennet, I.; O’Brien, W.; Gunay, H.B. Effect of Window Blind Use in Residential Buildings: Observation and Simulation Study. In Proceedings of eSIM2014, Ottawa, Canada, 8-9 May 2014.

14. Technology Strategy Board. Design for a Future Climate. In Exploiting the Opportunities of Adapting our Buildings; Technology Strategy Board: Swindon, UK, 2011.

15. Department for Communities and Local Government, The National Archives, 2010. Available online: http://www.communities.gov.uk/documents/planningandbuilding/pdf/1800841.pdf (accessed on 17 February 2015).

16. Contribution of Working Groups I, II and III to the Fourth Assessment Report of the Intergovernmental Panel on Climate Change; Pachauri, R.K., Reisinger, A., Eds.; IPCC: Geneva, Switzerland, 2007.

17. Ridley, I.; Bere, J.; Clarkec, A.; Schwartzb, Y.; Farrd, A. The side by side in use monitored performance of two passiveand low carbon Welsh houses. Energy Build. 2014, 82, 13-26.

18. NHBC Foundation; BRE Trust; Zero Carbon Hub. Overheating in New Homes: A Review of the Evidence; IHS BRE Press: Milton Keynes, UK, 2012.

19. Gupta, R.; Gregg, M. Using UK climate change projections to adapt existing English homes for a warming climate. Build. Environ. 2012, 55, 20-42.

20. CIBSE TM48. Use of Climate Change Scenarios, the CIBSE Future Weather Years; The Chartered Institution of Building Services Engineers: London, UK, 2009.

21. Office of the Deputy Prime Minister. Housing Health and Safety Rating System Operating Guidance, Housing Act 2004; Office of the Deputy Prime Minister: London, UK, 2006. 
22. CIBSE. Environmental Design: CIBSE Guide A, 7th ed.; CIBSE: London, UK, 2007.

23. Dea, R.D.; Brager, G.S. Developing an Adaptive Model of Thermal Comfort and Preference. ASHRAE Trans. 1998, 104, 145-167.

24. Lomas, K.; Eppel, H. Sensitivity analysis techniques for building thermal simulation programs. Energy Build. 1992, 1, 21-43.

25. Vringer, C.; Vringer, C.R. Analysis of the Requirements for Household Consumption. Environ. Assess. Agency 2015, in press.

26. Gram-Hanssen, K.; Larsen, T.; Knudsen, H.; Kanstrup, A.; Christiansen, E.; Mos-Gaard, M.; Brohus, H.; Heiselberg, P.; Rose, J. Occupants Influence on the EnergyConsumption of Danish Domestic Buildings: State of the Art; Aalborg University: Aalborg, Denmark, 2010.

27. Ridley, I.; Clarkeb, A.; Bere, J.; Altamirano, H.; Lewis, S.; Durdev, M.; Farr, A. The monitored performance of the first new London dwelling certified to the Passive House standard. Energy Build. 2013, 63, 67-78.

28. Bere, J. User Friendly Design; UK Passivhaus Conference: London, UK, 2013.

29. DesignBuilder Software Ltd. Available online: http://www.designbuilder.co.uk/ (accessed on 7 January 2015).

30. DesignBuilder Ltd. EN ISO 13790 Standard (2008) Tests for the Calculation of Energy Use for Space Heating and Cooling; DesignBuilder Ltd.: Stroud, UK, 2012.

31. ASHRAE. Handbook of Fundamentals, SI ed.; ASHRAE, American Society of Heating, Refrigerating and Air Conditioning Engineers: Atlanta, GA, USA, 2013.

32. ENERGYPLUS ${ }^{\mathrm{TM}}$. The Reference to EnergyPlus Calculations; U.S. Department of Energy: Washington, DC, USA 2014.

33. Mushtaq, A.; Charles, C.H. Uncalibrated Building Energy Simulation Modeling Results. ASHRAE HVAC\&R Res. 2006, 12, 1141-1155.

34. Technology Strategy Board. Building Performance Evaluation. In Use Performance and Post Occupancy Evaluation-Social Housing Passive House Prototypes; Technology Strategy Board: London, UK, 2014.

35. Bere Architects. Passive House Planning: Worksheet Directory, Passivhaus Varification for Larch House; Bere Architects: London, UK, 2010.

36. Greater London Authority. London's Urban Heat Island: A Summary for Decision Makers; GLA: London, UK, 2006.

37. Yene, A. A method of obtaining visual comfort using fixed shading devices in rooms. Build. Environ. 1999, 2, 85-91.

38. Carbonari, A.; Rossi, G.; Romagnoni, P. Optimal Orientation and Automatic Control of External Shading Devices in Office Buildings. In Proceedings of the 18th International Conference on Passive and Low Energy, Florianopolis, Brazil, 7-9 November 2001.

39. Gugliermetti, F.; Bisegna, F. External Shadings and Glazing Materials as Passive Systems to Improve Energy Consumption and Indoor Comfort in Office Buildings. In Proceedings of the AIVC International Conference, Lyon, France, 23-26 October 2002.

40. DesignBuilder Software. DesignBuilder Simulation + CFD Training Guide; DesignBuilder Ltd.: Stroud, UK, 2011. 
41. The Energy Saving Trust. Solid Wall Insulation Supply Chain Review Purple Market Research for the Energy Saving Trust and the Energy Efficiency Partnership for Homes; The Energy Saving Trust: London, UK, 2009.

42. Porritt, S.; Cropper, P.; Shao, L.; Goodier, C. Ranking of interventions to reduce dwelling overheating during heat waves. Energy Build. 2012, 55, 16-27.

(C) 2015 by the authors; licensee MDPI, Basel, Switzerland. This article is an open access article distributed under the terms and conditions of the Creative Commons Attribution license (http://creativecommons.org/licenses/by/4.0/). 